\title{
To Assess the Knowledge of Mothers in Relation to Selected Aspect of Immunization: A Review
}

\author{
Harshada Kishor Joshi', Suchita Sawant ${ }^{2}$, Shweta Rasaria ${ }^{3}$ \\ 'Department of Mental Health Nursing, Bombay Hospital College of Nursing, Mumbai, Maharashtra, India, ${ }^{2}$ Department of Medical Surgical Nursing, Bombay Hospital \\ College of Nursing Mumbai, Maharashtra, India, ${ }^{3}$ Department of Child Health Nursing, Bombay Hospital College of Nursing, Mumbai, Maharashtra, India
}

\section{Abstract}

Review of literature is important for having a broad understanding of the problem. It is done to obtain scientific material relevant and specific to this study. It is a key step in the research process. Review of literature refers to an extensive and systematic examination of the publication relevant to the research project. India is the second most popular country in the world with a population of 1.02 billion. An estimated 400 million are children between 0 and 5 years. India has recorded many gains in the recent past between 1991 and 2001 . The country, however, faces several challenges that include: The infant mortality rate in 2000 was 68 , which has come down from 80/1000 live birth in 1990. Between 1997 and 2000, routine immunization coverage was from 60\% to 40\%. The primary purpose of reviewing relevant literature is to gain a broad background or understanding of the information related to the research problem of interest that is available. This review article assessed to knowledge regarding immunization among the mothers having under-five children and found that the majority of women had inadequate knowledge related to immunization. Hence, there is a need to spread awareness on immunization among the mother and community.

Keywords: Children, immunization, mother, vaccines

\section{INTRODUCTION}

The review of literature is locating, reading, and evaluating report of research as well as report on causal observation and opinions that are related to the individual research projects. The primary purpose of reviewing relevant literature is to gain a broad background understanding of the information related to the research problem of interest that is available.

A review of the literature is important for having a broad understanding of the problem. It is done to obtain scientific material relevant and specific to this study. It is a key step in the research process.

A review of the literature refers to an extensive and systematic examination of the publication relevant to the research project.

Access this article online

Website: http://innovationalpublishers.com/Journal/ijnmi

ISSN No: $2656-4656$

DOI: $10.31690 / \mathrm{ijnmi} / 54$
India is the second most popular country in the world with a population of 1.02 billion. An estimated 400 million are children between 0 and 5 years. India has recorded many gains in the recent past between 1991 and 2001. The country, however, faces several challenges that include:

The infant mortality rate in 2000 was 68 , which has come down from 80/1000 live birth in 1990. Between 1997 and 2000 , routine immunization coverage was from $60 \%$ to $40 \%$.

The primary purpose of reviewing relevant literature is to gain a broad background or understanding of the information related to the research problem of interest that is available.

This review article is organized under the following heading:

- Studies related to the importance of immunization

- Studies related to side effects of selected injectable immunization

- Studies related to the management of side-effects of selected immunization

- Study related to knowledge of mother regarding immunization

- Study related to the effect of planned teaching.

\section{Address for Correspondence:}

Mrs. Shweta Rasaria, Department of Child Health Nursing, Bombay Hospital College of Nursing, Mumbai, Maharashtra, India.

E-mail: harshadajoshi96@gmail.com

This is an open-access journal, and articles are distributed under the terms of the Creative Commons Attribution Noncommercial Share Alike 4.0 License, which allows others to remix, tweak, and build upon the work non-commercially, as long as appropriate credit is given and the new creations are licensed under the identical terms 


\section{Studies Related to Importance of Immunization}

Research involving children was important for all because they were vulnerable groups and had a right to protection and has to be shielded from undue risk. An important aspect of child care was to protect the child against specific infectious diseases. These childhood diseases were prevented by vaccines. The vaccines against these diseases stimulated the child's body to produce immunity against specific infections. Therefore, immunization was truly a chance for every child's survival.

The informed cooperation of the people, the unwavering commitment of leaders, the devotion of health worker, the loving care and intelligent interest of parents, the rising of necessary funds, and materials were the vital ingredients to give life to all children of the world.

Immunization of the children of under-five age was important to protect the child from six killer diseases. These infections were prevented by giving injectable immunization in children. Vaccine is an immune-biological substance designed to produce specific protection against disease. It stimulated the protective antibody and immune mechanism vaccine may be prepared from live modified vaccines organism, inactivated or killed organism extract cellular fraction toxoid or combination of these.

Immunization had done more to prevent disease than most medical procedures. The introduction of live or killed organisms or a modified part of the organism into a host capable of increasing effective immune response resulted in active immunity, and such immunity could be long-lasting and could be further prolonged with booster immunization.

Immunization was the most cost-effective public health intervention to reduce morbidity and mortality. Following the success in eradication of smallpox in the seventies, the Expanded Programme of Immunization was launched to control six vaccine-preventable diseases, namely, diphtheria, pertussis, and tetanus (DPT), poliomyelitis, and tuberculosis. In November 1985, the scope of the program was universalized and measles vaccination was included in the program. It was targeted to cover all pregnant women with immunization against tetanus and all infants with primary immunization. In 1992, this program became part of child survival and safe motherhood program. Following in International Conference on Population and Development held at Cairo (1992) a paradigm shift was brought about and Reproductive and Child Health (RCH) Programme was launched in October 1997. Immunization is an important component of the RCH program..$^{[1-10]}$

With the advent of the immunization program in the United States had reduced the number of vaccine-preventable diseases by more than $99 \%$ in the past $20 \%$ of one could say that it was no more a problem in the developed nation today. It was a serious problem in developing countries and adequate information had now been collected to show that these were associated with high mortality and morbidity in different parts of the developing and underdeveloped countries.
A mass immunization program was one of the largest slums of Asia, Dharavi in Bombay in 1984. The mothers attending the urban health center with children were fully immunized and $51.60 \%$ were not immunized at all. The common reason expressed for not carrying out immunization was lack of knowledge $(70.5 \%)$, lack of time $(20 \%)$, and lack of faith in the efficacy of immunization program resulted in gradual decline of the vaccine-preventable diseases concerned.

The WHO had declared three distinct objectives for the year 2000 A.D., i.e., polio eradication, neonatal tetanus elimination, and measles reduction. However, none of the targets had been achieved so far. The revised target for the certificate of polio eradication was by 2005 .

In spite of nationwide immunization program, the incidence of the vaccine prevented disease remained almost same according to the survey report on the immunization profile of India estimated by WHO, UNICEF, 2004.

Hence, there was definite need to assess the impact of missed opportunity on immunization coverage in urban as well as rural were as and to try and find out the reasons for their occurrence and how to strengthen the immunization practice.

According to the researcher, a study was done to compose the immunization status of primary school children of a government school with those of private school primary. Immunization status of 1300 primary school revealed that about $25 \%$ children received Bacillus Calmette-Guerin (BCG) vaccination, as compared to polio and DPT vaccination only $2 \%$ children of private school and $0.33 \%$ of government school had failed vaccination as per schedule.

Immunity of diphtheria depends on antibody production against the exotoxin produced by " $\mathrm{C}$ " diphtheria-A circulating diphtheria anti-toxin level of the $0.110 / \mathrm{ml}$ was bared to provide clinical immunity against the disease used extensively and was to be provided strongly. The procedure was carried out by means of injection of diphtheria toxin which had been modified in such a manner as to make it harmless. For several decades, inactivated whole cell pertussis vaccine had been part of national immunization program and proved to be highly effective. A never a cellular pertussis vaccine had been developed that countered equal protection but was relatively less lactogenic.

Both whole cell or a cellular vaccine were administered in combination with diphtheria and tetanus toxoids, immunization of infants had shown a similar efficacy of $80 \%$ or more in preventing typical pertussis and reducing related morbidity and mortality. ${ }^{[1-14]}$

\section{Studies Related to Side Effects of Primary INJECTABLE IMMUNIZATION}

Immunizations were among the most oversize medical procedure for healthy infant and children. In general, intramuscular administration was preferred for most vaccines. 
In infant and young children, the anterolateral thigh is preferred site; in other children, the deltoid muscle can be used. This intramuscular administration of vaccine was one of the most common causes of childhood iatrogenic pain and other reaction such as swelling, redness, tenderness, and development of small nodules or sterile abscess. Furthermore, at site of infection, general reaction may be fever, malaise, headache, and other constitutional symptoms.

Modern vaccines although safe and effective can be associated with adverse event ranging severity from mild to life threatening. In addition because of no vaccine can be expected to be completely effective, some person may develop diseases after exposure despite vaccination. Vaccine component can cause allergic reaction in some recipient. These components include the protective antigen, other component of microorganisms, animal proteins introduce during vaccine production antibiotics, and other preservative or stabilizers such as gelatin. Reaction may be local or systemic including anaphylaxis and urticaria. Local or systemic reaction results from too frequent administration of some vaccine.

Faulty technique may be related to faulty production of vaccines, inadequate detoxification, too much dose, improper immunization site or route, and incorrect diluents in correct preparation etc.

A long needle produced fever reaction than a short thin needle. He has been shown that practitioner prefer to use the short or long needle and did so regardless of any recommendation, if appears that side effect are fever when the muscle is penetrated rather than subcutaneous tissue. A vaccine basically contains the active antigens, suspending fluid, preservatives, and adjuvant. The adverse reaction can arise from any of the contents of the vaccine, faulty technique, for example, use of wring dilutes, unsterile syringes and needle, lack of aseptic technique, wrong site of injection, and hypersensitivity reaction. The type of local reaction and systemic reaction is explained below:

\section{Local reaction}

Most injectable vaccine causes some local reaction including pain, slight swelling, and aseptic nodule, while lack of aseptic care and use of contaminated needle and syringe can result in an abscess. Other local reactions include urticarial rash and reactions resembling Arthurs phenomenon.

\section{Systemic reaction}

Fever is the most common general reaction. Neurological complications include convulsions, encephalopathy, and occasionally paralysis. Epileptic episode is the most common neurological complications, which can occur after use of whole cell pertussis, measles vaccines. Encephalopathy can also occur in one in 1 million doses injected.

\section{BCG}

Lymphadenopathy, especially in left axilla or left supraclavicular region, is noted after BCG vaccine. It can also cause osteitis or osteolysis in left humerus. Mostly these reactions are due to faulty injection technique. Thrombocytopenia, viral hepatitis, and reactivation of some conditions such as tuberculosis can occur after vaccination. Hence. BCG vaccination is contraindicated in immune-deficient children and children receiving corticosteroids.

\section{DPT}

Modern pain at the site of injection, also mild fever or high grade convulsion, abscess formation, serum hepatitis can occur after DPT vaccines. Hypotonic hyporesponsive shock was specific to DPT vaccine, besides discomfort and local pain and swelling which occur in 30\%-40\% cases. DPT can also cause high pitched persistent crying lasting for 2-3 h. Convulsions, encephalopathy, and Reyes syndrome can also follow DPT and it also can perceptible infantile spasms in babies who are potentially at risk. Renal complications include transient proteinuria, and hematuria, acute nephrosis and nephritic manifestation can be caused by DPT vaccines. Neurological involvement cause paralytic accident provocative reactions, for example, administration against diphtheria by DPT vaccine. About $2 \%-8 \%$ of children develop fever of $39^{\circ} \mathrm{C}$ or higher and that of 5-105 get swelling and pain lasting more than $48 \mathrm{~h}, 50 \%$ develop local reaction, there are many causes for these disease from which we have protect the children mode of transmission and reservoir have to be identified and have to educate the family and community about these causes.

\section{Measles}

Side effects of the measles vaccine include transient rashes and fever which may begin 5-12 days after vaccination and last several days. Adverse reactions include joint pain, low grade fever, rash, and lymphadenopathy 5-12 days after vaccination. Children should be skin tested for tuberculosis before measles vaccine administration because measles virus can cause tuberculosis to become systematic. Killed measles vaccine induced incomplete humoral immunity and cell mediated hypersensitivity, resulting in the development of a syndrome of atypical measles in some children after subsequent infection by wild type virus.

\section{Common side effect of primary injectable vaccines}

Toxic shock syndrome is due to acute staphylococcal infection. This was described after the use of single or combination of vaccines. The important reason for this syndrome is contaminated diluents, lack of aseptic care, keeping in the reconstituted vaccine, and using it after $2-3 \mathrm{~h}$. The syndrome is characterized by fever, vomiting, diarrhea, and shock which may prove fatal.

Vaccines may produce separation of immunity because of leukemia or patient who is on corticosteroids therapy. These vaccines may give rise to side effects because of their hypersensitivity or because of their neurological problems. These vaccines are prepared in combination so the interaction may be more.

There are some hazards of immunization. A vaccine basically contains the active antigens, suspending fluids, preservatives, and adjuvants. The adverse reactions can arise for any of the contents of the vaccine or due to faulty technique. 


\section{Studies Related to Management of Side Effect OF INJeCtable ImMUNIZATION}

Vaccinating infants with long needle were non-inferior to a narrow short needle for immune response and reduced local reaction.

Immunization guideline in several countries recommended the use of short thin needle and WHO recommends that needle should be perpendicular to the skin when the injection is given. However, in practice many nurses and practitioner tends to keep the needle at $45^{\circ}$ to the skin, thus causing more reaction. It had been suggested that the recommendation should be changed to recommend the use of the 23 or 25 $\mathrm{mm}$ gauge needle but like all change this had been slow in coming.

As looked to the future of childhood immunization in industrialized countries, there was increasing attention to address the challenge, envisioned of being addressed include enlacing access to immunization services abbreviating immunization schedules and administering vaccines without the use of needle.

As mentioned above the importance of alternative routes of administration of vaccines that can both simplify the immunization schedule and improve the acceptability to parents of adding get more antigens by avoiding the use of needle. Oral immunization was one strategy.

Phenobarbital $5 \mathrm{mg} / \mathrm{kg}$ can be used to control convulsion. Diazepam 5-10 mg is most useful.

Hospitalization and intensive care may be required for management of toxic shock syndrome and paralysis. The general approach was vigorous fluid therapy to correct hypervolemia, use of vasopressor drugs for maintaining blood pressure and appropriate antibiotics such as second or thirdgeneration cephalosporin, cloxacillin.

Role of corticosteroids was controversial but in case of shock, high dose steroids over a short period of time may be useful. Toxic shock syndrome and paralysis also needed to be investigated properly. The reaction of DPT, i.e., moderate pain at the site of injection also mild fever or high-grade fever, convulsion may occur. Abscess formation, hepatitis could occur after DPT vaccine. These reactions could be avoided by good sterilization and aseptic precaution and also immunocompromised children.

Regular vaccination and proper management could prevent the complications of the injectable immunization and helped to prevent child mortality and morbidity and also helped to ensure a good health of children and could help to protect their rights. Appropriate training to the mother after immunization in pain recognition and assessment of child was the key of this goal.

Simple analgesics such as paracetamol and nonsteroid antiinflammatory drugs were the first-line therapy in most pediatric pain after immunization. Despite this there was surprising lack of strong evidence relating to their optimal use.

However, a recent study on the management of pain in pediatric demonstrated that even when using paracetamol alone, the mean small dose was well, before the recommended maximum dose. Paracetamol could be used to relieve pain and pyrexia. It could be administered 8 hourly for 1-2 days and tranquilizer was also useful in reaction like high pitched incessant crying following DPT and measles vaccine, surgical procedure such as incision and drainage may be required after abscess, formation of cessated lymph node after BCG vaccination.

A major reason that parents did not bring children for routine immunization was that they did not know what was required. Fully inform the parents about when it is to be given and what could be side effects expected. Children may develop a low grade fever after immunization. Counsel parents to give acetaminophen or children's ibuprofen for a fever of more than $101^{\circ} \mathrm{F}\left(38.4^{\circ} \mathrm{C}\right)$.

Parents should report any untoward symptoms of immunization, such as high fever, unfavorable reactions are most likely to occur within a few hours or days of administration. With live attenuated virus vaccines, viruses can multiply, so reaction may occur up to 60 days later make copy and urge parents to keep such records at home as well. They would need this information.

\section{Study Related to Knowledge of Mother Regarding Immunization}

The immunization coverage is not uniform in India. A study of knowledge of mother; attitude and practices on immunization in urban slums of Bijapur city, Karnataka, India, result mother's perceptions and knowledge: Majority of the respondents $(65.16 \%)$ opined that disease could be prevented by immunization, while only $11.61 \%$ could name two or more disease that could be prevented by the immunization schedule. No respondent could name more than three of disease and $61.16 \%$ could not even name one.

Forty-six respondents $(29.98 \%)$ were of the opinion that it was important to give all the doses in the immunization schedule, while only $18(11.61 \%)$ knew when the dose had be given. Among the 101 respondents who said that disease could be prevented by immunization only, 43 children were fully immunized. Even though 46 respondents opined that it was important to give all dose of the immunization schedule. Only 26 children among these were fully immunized.

By study mother's awareness and knowledge of under 5 year children regarding immunization in Minia city, Egypt, present study revealed that a total of 97 mothers between age group of 20 and 40 year were assessed. It was found that nearly half $46.4 \%$ of higher educated mother gave vaccination at time compared with $50 \%$ of illiterate mother did not give their children vaccination at time with high statistically differences $(P=0.001)$. By study on immunization among the mothers 
of under-five children, Belgium, Karnataka result the mean knowledge vaccination immunization of mother of under-five children was $58 \%$ and attitude score was 41.4 by study done on Subharti Medical College, Dehradun, India, results $92 \%$ of mother have lack of knowledge about immunization.

Assessment of knowledge toward immunization among mothers under five of U.P. India study findings are that the data collected were analysis using descriptive and statistics. Knowledge score can be categorized in good, average, and poor. Good knowledge score: It is range from 12 to 15 and there were three mothers achieved good score and percentage of knowledge is $10 \%$. Average knowledge score: It is range from 8 to 11 and there were 7 months achieved average score and the percentage of average knowledge is $23.34 \%$. Poor knowledge score: Fourteen is range from below 8 and there were 20 months achieved poor score and the percentage of poor knowledge is $66.67 \%$.

A study of knowledge, attitude, and practice (KAP) on immunization of children in urban slum of Bijapur city, Karnataka, India, shows results that immunization coverage in the urban slums of Bijapur is still way short of $85 \%$ average mark. A lack of information and motivation among the parents is the men reasons for this dismal scenario.

A study on knowledge and attitude regarding vaccines among mothers of under-five children in selected hospital at Mangalore result shows more than half of the mothers 184 (61.3\%) has good knowledge regarding vaccines. In a similar study, KAP study done by Shamila Hamid in North Kashmir (2011), about "immunization of children in a rural area of North Kashmir." India: A KAP study $99 \%$ of mother were ignorant about use of BCG used. It revealed 39\% of knowledge about BCG. Therefore, the findings of the study show that Primary Health Care nurse have a key role is creating health consciousness among the people and also identify children who are risk by periodic assessment of children. Mother needs education on importance of National Immunization Schedule.

\section{Study related to Effect of Planned Teaching}

The field of preventive and social medicine is improving with new concepts, changes, and inventions, still people are facing lots of health problems in spite of measures taken through National Health Programme.

The research method adopted for the study was preexperimental research design with an evaluative approach. Purposive sampling method was used to select 100 mothers of under-five children. Most of the samples (34\%) were in the 23-27 years of age group and only (15\%) samples were in 33 and above year's age group. Majority of samples 32\% were graduate and $6 \%$ were postgraduate.

There were $83 \%$ mothers who had information regarding immunization schedule, importance, and child care after immunization. However, 39\% mothers received knowledge from health personnel, $28 \%$ mothers received information from mass media, 18\% got knowledge from close relatives, and $17 \%$ mothers received information from neighbors. This study indicated that the health personnel plays major role in spreading the awareness about the immunization. Mother had better knowledge about general immunization schedule. Maximum mothers (56.75\%) were having knowledge regarding general immunization in pre-test and $80.25 \%$ in post-knowledge score. The planned teaching on selected immunization was proved to be effective in delivering the knowledge and awareness.

In India, 72 babies are dying for every 1000 babies born in a year. Disease of early childhood preventable by vaccination remains a serious problem in developing countries. The major communicable diseases prevented by the vaccination are diphtheria, tetanus, and hemophilus influenza type $\mathrm{B}$, whooping cough, tuberculosis, poliomyelitis, mumps, rubella, and hepatitis B. An evaluative approach with Quasiexperimental - two group pre-test design was adopted. The sample comprised 100 mothers who delivered first baby in the selected hospitals. The reliability coefficient was found to be $\mathrm{r}(10)=0.92$.

The study revealed that the mean and standard deviation of post-test knowledge score of mothers in experimental group $(27.80 \pm 3.010)$ was much greater than pre-test value $(10.44$ $\pm 2.323)$.

There was no change in pre- and post-test knowledge score in control group $(9.74 \pm 1.805)$. The teaching package was effective on levels of mothers knowledge. It was supported by a study on effectiveness of planned teaching program regarding immunization among mothers of under-five children in selected hospital. The findings revealed that the post-test knowledge score (26.53) was higher than the pre-test knowledge score (13.5\%). Therefore, planned teaching program was found to be an effective media for educating mothers regarding importance of immunization.

This study found out that there was significant association between level of knowledge and selected demographic variables in experimental group such as area of residence. Hence, the research hypothesis was accepted and null hypothesis was rejected and in control group.

Childhood is very precious period in human life cycle. It requires more care and protection from the diseases. Vaccination are meant to protect the children against a variety of preventable diseases and hence, it is every child's right to be vaccinated. A study was conducted in a selected village on the mothers, antenatal women. The sample size was 60 . The study reveals that the findings were: About $76.7 \%$ were between the age group of 21 and 25 years, $18.3 \%$ were between the age group of 26 and 30 years, and only 5\% were between the age group of 31 and 35 years. About 100\% antenatal mothers agreed that immunization was beneficial for their children.

The findings of pre-test data showed that $41.66 \%$ were having moderately adequate knowledge while $58.33 \%$ had inadequate 
Table 1: Number of reported cases in the year 2003

\begin{tabular}{lc}
\hline Immunization & Cases \\
\hline Diphtheria & 3914 \\
Pertussis & 28,985 \\
Measles & 44,004 \\
Polio - & 225 \\
Neonatal tetanus & 1691 \\
\hline
\end{tabular}

knowledge. Findings of post-test showed that $46.66 \%$ of the respondents possessed adequate knowledge as compared to $53.33 \%$ of the respondent noticed with moderate adequate knowledge. ${ }^{[15,16]}$

Comparison of pre-test and post-test knowledge scores of antenatal mothers regarding immunization, the obtained " $t$ " value 25.508 was greater than the table value Table 1 .

The study assessed the knowledge regarding immunization among antenatal mothers and found that the majority of women had inadequate knowledge related to immunization. After planned teaching on immunization there was significant improvement in the knowledge of the antenatal mothers regarding immunization.

\section{Conclusion}

This review article assessed to knowledge regarding immunization among the mothers having under-five children and found that majority of women had inadequate knowledge related to immunization. Hence, there is the need to spread the awareness on immunization among the mother and community.

\section{RefEREnCES}

1. Behrman RE. Nelson: Textbook of Pediatric. $17^{\text {th }}$ ed. Amsterdam: Elsevier; 2006.

2. Dagnew AF, Hussein J, Abebe M, Zewdie M, Mihret A, Bedru A, et al.
Diagnosis of latent tuberculosis infection in healthy young adults in a country with high tuberculosis burden and BCG vaccination at birth. BMC Res Notes 2012;5:415.

3. Diggle L. Management in immunization. Arch Dis Child 2007;92:1105-8.

4. Harrop JE. Pain management in pediatric. Arch Dis Child Educ Pract 2007;92:20-6.

5. John TJ. Indian pediatrics. J Indian Acad Pediatr 1999;36:461-3.

6. John J. Pediatric clinics of North America. Child Immun 2000;47:2.

7. Panari H, Anuchithra. Study on immunization among the mothers of under five children, Halaga Village, Belgaum, Karnataka. Asian J Nurs Educ Res 2016;6:191.

8. Ministry of Health and Family Welfare. Immunization Handbook for Medical Officer. New Delhi: Ministry of Health and Family Welfare, Government of India; 2009.

9. Kukarni NJ. Vaccination, What's the Confusion? Mumbai: The Times of India; 2005.

10. Bhore NR, Pujari K, Dhanwade A. Planned health teaching programme regarding legal aspects. Sinhgad e-J Nurs 2014;4:1-4.

11. Prathiba V, Umarani J. Teaching package improves mothers knowledge on vaccine preventable diseases and vaccination: A quasi experimental study. Int J Res Med Sci 2014;2:976-82.

12. Varghese R, Swami GN, Patel SV, Patel V, Patel V. Effectiveness of planned teaching programme on knowledge regarding immunization among antenatal mothers at selected villages of Waghodia Taluka. Int J Appl Res 2016;2:157-60.

13. Baru R, Acharya A, Acharya S, Kumar AS, Nagaraj K. Inequities in access to health services in India: caste, class and region. Econ Polit Wkly 2010;18:49-58.

14. Torisu M, Miyahara T, Shinohara N, Ohsato K, Sonozaki H. A new side effect of BCG immunotherapy BCG-induced arthritis in man. Cancer Immunol Immunother 1978;5:77-83.

15. Sujatha RM. A study on knowledge and attitude regarding vaccines among mothers of under five children attending pediatric OPD in a selected hospital at Mangalore. IOSR J Nurs Health Sci 2014;3:39-46.

16. Agarwal G, Bithu KS, Agarwal R. An epidemiological study of acute poisoning in children in a tertiary care hospital of Western Rajasthan, India. Int J Contemp Pediatr 2016;3:1249-51.

How to cite this article: Joshi HK, Sawant S, Rasaria S. To Assess the Knowledge of Mothers in Relation to Selected Aspect of Immunization: A Review. Int J Nurs Med Invest. 2019;4(4):68-73. 